VENEI

Encontro Nacional de Economia Industrial e Inovaçāo

FACE-UFMG

Inovação, Sustentabilidade e Pandemia 10 a 14 de maio de 2021

\title{
Estratégias Tecnológicas na Indústria de transformação do Brasil: Um estudo a partir das atividades inovativas
}

\author{
Tatiana Massaroli de Melo (UNESP); \\ Rogério Gomes (UNESP); \\ Enéas Gonçalves de carvalho (UNESP)
}

Resumo: $\mathrm{O}$ objetivo deste artigo é identificar as estratégias tecnológicas adotadas na indústria de transformação brasileira. As estratégias tecnológicas foram analisadas a partir da construção de indicadores de inovação e de imitação de produto e de processo - além de um indicador adicional para inovações organizacionais e de marketing. Os indicadores foram aplicados a 19 setores da indústria brasileira de transformação (PINTEC, 2014) e nas contrapartes de um conjunto de países europeus selecionados (CIS, 2016). Para efeitos de análise, os setores industriais foram agrupados segundo o critério de intensidade tecnológica proposto pela OCDE e os resultados confrontados com os padrões setoriais de inovação. As conclusões apontaram que as estratégias predominantes na indústria brasileira são as passivas, em detrimento das ativas.

Palavras-chave: Estratégias; Estratégias de Inovação; Atividades Inovativas; Indústria Transformação.

Código JEL: O32; O33

Área Temática: 3.3

Espaço reservado para organização do congresso. 


\section{Introdução}

O estudo da estratégia tem uma longa tradição no campo da 'arte militar' (Mintzberg et al., 2006; Ancona, 1989; Whittington, 2001) e, mais recentemente, tem sido também tema de pesquisas nas ciências sociais. Nesta área, os administradores de empresas, principalmente, e os cientistas políticos têm se destacado na incorporação da noção às suas abordagens teóricas e às suas metodologias de pesquisa (Rumelt et al., 1991; Mintzberg et. al., 1998; Simon, 1986 e 1993; Lindblom, 1981). Complementarmente, pode-se mencionar, ainda, alguns destacados historiadores econômicos e da tecnologia, como, por exemplo, A. Chandler, D. Hounshell, W. Lazonick, P. David e N. Rosenberg.

Diferentemente do que imaginou Marshall ${ }^{1}$, os economistas que o sucederam, principalmente os da corrente dominante, jamais deram maior destaque à noção/conceito de estratégia. Uma exceção parcial, mas ainda assim digna de nota, foi o caso da teoria dos jogos, que adotou, entretanto, uma acepção muito limitada do conceito de estratégia. Além de ser incompatível com a concepção mais usual, o enfoque de estratégia dessa abordagem se configurou mais como uma extensão específica da conhecida teoria da utilidade subjetiva esperada do que numa real incorporação da noção de estratégia à teoria econômica (Simon, 1986 e 1993; Ancona, 1989).

Ao longo das várias gerações, um número limitado de economistas tem empregado, de maneira mais ou menos explicita, a noção/conceito de estratégia. Mais recentemente, diferentes economistas têm incorporado as estratégias aos seus temas de estudo e de pesquisa (Langlois, 2003; Rumelt et a l., 1991; Pavitt e Steinmueller, 2002; Freeman e Soete, 1997; Loasby, 2010; Foss e Stieglitz, 2012).

Entretanto, entre os economistas que têm dado destaque a este conceito, a maior parte é de autores heterodoxos, especialmente aqueles voltados para pesquisas na área das inovações e das mudanças tecnológicas, em especial, a corrente evolucionista/neo-schumpeteriana, que tem utilizado noções mais específicas de estratégias inovativas e/ou tecnológicas.

O objetivo deste artigo é identificar as estratégias tecnológicas da indústria de transformação brasileira. Nesta perspectiva, o estudo compara, hierarquiza e classifica as estratégias inovativas na indústria brasileira por meio do confronto com as experiências de um conjunto de países europeus selecionados. Para isto, foram elaborados indicadores de intensidade tecnológica a partir dos resultados das pesquisas PINTEC (2014) para o Brasil e dos surveys CIS (2016) para os países europeus, que compartilham a metodologia proposta pelo do Manual de Oslo da OCDE (OCDE, 2005). A construção dos indicadores de intensidade baseouse na noção de que os tipos de inovação - principalmente, mas não estritamente tecnológicas são incorporados aos produtos, aos processos às organizações e ao marketing. Ademais, admitese que as estratégias inovativas podem ser agrupadas em duas classes específicas de setores: aqueles intensivos em inovação e aqueles intensivos em imitação. $O$ resultado dessa sistematização foi a construção de 5 métricas de intensidade tecnológica definidas ao nível setorial: (i) setores intensivos em inovação de processo; (ii) setores intensivos em inovação de produto; (iii) setores intensivos em imitação de processo; (iv) setores intensivos em imitação de produto; (v) setores intensivos em inovações organizacionais e de marketing.

A análise realizada está baseada em três conjecturas principais. A primeira é que as estratégias de inovação podem ser analisadas a partir dos procedimentos inovativos adotados e medidos pelos indicadores de intensidade. A segunda é baseada na noção de que uma boa

\footnotetext{
${ }^{1}$ No Apêndice C ao Vol. II (da edição brasileira) dos Princípios de Economia, Marshall tratou com destaque da noção de estratégia. "Só recentemente, e em grande parte graças à influência salutar das críticas da Escola Histórica, foi dada preeminência, em Economia, a uma distinção correspondente à existente entre estratégia e tática na parte bélica" (Marshall Vol. II, 1985:353, ênfase acrescentada).
} 
estratégia tecnológica é aquela que segue a trajetória tecnológica esperada para a indústria (Pavitt, 1984; Marsilli, 2001; Castellacci, 2008) e, portanto, permite comparar as estratégias estabelecidas por meio dos indicadores com o "padrão esperado" para o regime tecnológico. A estes dois pressupostos adicionou-se um terceiro, que delimita o escopo das estratégias tecnológicas: supondo que estas últimas guardam uma certa correspondência com o comportamento das estratégias inovadoras propostas pela tipologia de Freeman e Soete (1997).

Além desta introdução, o artigo possui três seções. A segunda seção parte de uma breve discussão da teoria da tomada de decisão para propor uma tentativa de definição de estratégia a partir das ideias desenvolvidas por Simon (1993). A terceira aborda as estratégias de inovação, dando destaque às estratégias tecnológicas. A quarta seção se inicia com a descrição da base de dados utilizada, prossegue abordando os indicadores elaborados para este estudo, avança com a avaliação dos resultados obtidos e conclui com uns breves comentários metodológicos. As considerações finais são apresentadas na última seção.

\section{A teoria da tomada de decisão e estratégias}

No âmbito do que é conhecido como teoria da tomada de decisão, o que tem prevalecido é a abordagem normativa (ou prescritiva), com especial destaque para a influente teoria da utilidade subjetiva esperada. Essa teoria define as condições de perfeita racionalidade e de maximização de utilidade em um mundo de certeza ou em condições em que as distribuições de probabilidade de todas as variáveis relevantes estão disponibilizadas aos tomadores de decisões (Simon, 1986: 2; Vercielli, 1999; Fishburn, 1987; Arthur, 1992).

Em síntese, a teoria da utilidade subjetiva esperada pressupõe que: 1) o tomador de decisão tenha uma função de utilidade bem definida e, portanto, seja capaz de estabelecer uma relação cardinal como unidade de medida de sua preferência com relação a um conjunto específico de eventos futuros; 2) o tomador de decisão poderá estipular a totalidade das séries futuras de eventos e, assim, estabelecer uma distribuição conjunta de probabilidades (objetiva ou subjetiva); 3) o tomador de decisão se confronta com um grupo de possibilidades bem definido a partir do qual poderá fazer a sua escolha; e 4) o tomador de decisão optará pela alternativa ou a escolha que maximiza o valor esperado da sua função de utilidade (Simon, 1983). Esta teoria enfrenta, entretanto, problemas difíceis sempre que ocorre conflito de interesse real ou potencial, comportamento não coerente e, especialmente, quando eles são combinados com incerteza, informação incompleta e racionalidade limitada (Simon, 1986 e 1983; Shackle, 1992; Sen, 1987).

A teoria dos jogos, formulada em 1944 pelo matemático Von Neumann e pelo economista-matemático Morgenstern, foi, provavelmente, a tentativa mais ambiciosa e matematicamente sofisticada de responder às questões colocadas à teoria da utilidade subjetiva esperada (Simon, 1986 e 1983). O enfoque característico da teoria dos jogos considera que os agentes: (1) são tipicamente racionais - isto é, suas preferências são compatíveis com os axiomas da teoria da escolha racional e, portanto, eles podem ser tratados como maximizadores de utilidades subjetivas esperadas; (2) têm conhecimento igual e comum da sua racionalidade e pleno das regras do jogo. Todavia, alertando criticamente às consequências de tais pressupostos, Simon (1986: 7- 8) ressalta que o argumento da escolha racional somente pode ser aceito ao assumir que o curso de uma ação se impõe aos demais, o que torna a escolha maximizadora preferível a todas as outras. No entanto, não é possível garantir que existirá sempre uma ação que se imponha às demais, sendo plausível assumir que um conjunto de soluções alternativas é igualmente coerente com as premissas de racionalidade.

Dado que a estratégia é tradicionalmente associada à escolha, compreender a forma particular como o processo de escolha é realizado, a partir dos pressupostos adotados, torna-se crucial para o estudo do conceito de estratégia. No âmbito da teoria dos jogos, o termo estratégia é empregado numa acepção muito específica (e restritiva) e não é compatível com a maneira com que a noção tem sido mais frequentemente adotada no âmbito das ciências sociais ou mesmo na maior parte das abordagens das estratégias de inovação e da tecnologia. (Freeman e Soete, 1997; Tidd et al., 2005; Pavitt e Steinmueller, 2002). Nessa primeira abordagem, estratégia está associada à escolha, mas não uma escolha qualquer, pois há interdependência das 
ações: o agente não tem conhecimento completo, pois não sabe o que fará seu oponente, mas sabe aquilo que o seu oponente pode fazer, uma vez que supostamente tem conhecimento de todas as possibilidades de ação (Shackle, 1992: 161 e 183). Embora o resultado exato não seja conhecido, o resultado não representa uma novidade (Georgescu-Roegen, 1971:122). Não se trata, portanto, de uma situação de escolha racional típica, mas de uma "escolha quase-racional de conduta" (Shackle, 1992: 183).

\subsection{Estratégias: contextualização}

Contrariamente à visão tradicional da teoria dos jogos, a acepção mais difundida da noção de estratégia, e que é adotada neste artigo, considera a presença de novidade ou imprevisto como o elemento mais poderoso das decisões estratégicas (Shackle, 1992: 161). Neste sentido, não é possível especificar uma escolha que seja superior às demais, pois cada uma delas implica o surgimento de surpresas genuínas. Esta seção procura organizar as abordagens alternativas à visão tradicional do processo de tomada de decisão, baseado na escolha racional, com vistas a buscar algum avanço conceitual a partir de uma perspectiva teórica apropriada ao estudo das estratégias inovativas.

Esta tarefa pode ser iniciada a partir das contribuições de Simon (1986, 1983 e 1993) no âmbito da chamada teoria da tomada de decisão em geral e, em especial, no campo mais específico da estratégia. $\mathrm{O}$ autor propôs uma definição específica e bastante concisa ao afirmar que estratégia é a tomada de decisão que lida com as metas fundamentais das organizações (Simon, 1993: 131) $)^{2}$. Além de um ponto de partida, essa noção de estratégia é compatível com a maior parte das características principais que a ela são usualmente atribuídas (Langlois 2003; Mintzberg et al. 1998).

Não obstante a falta de consenso quanto à definição da noção de estratégia, existe, entretanto, uma razoável concordância relativamente às suas características principais. Assim, considera-se que elas: 1) afetam uma firma inteira ou, pelo menos, uma parcela significativa da mesma - uma unidade estratégica de negócios, por exemplo; 2) dizem respeito, por natureza, ao longo prazo e se baseiam mais nas concepções quanto ao futuro (previsões e expectativas) do que em conhecimento sólido; 3) são atribuição dos administradores do mais alto nível da empresa ou, no mínimo, do nível divisional; 4) incluem as escolhas de produtos e de serviços a oferecer e o curso de ação necessário para viabilizá-los; 5) abarcam a concepção e a configuração dos planos de ações que determinam de que maneira a empresa se posiciona para a competição no mercado; 6) implicam a escolha de um escopo e de uma diversificação adequada (Langlois, 2003; Mintzberg et al. 2006).

Complementarmente, pode-se postular que as estratégias - habitualmente caracterizadas por processos em três etapas (concepção, implementação e adaptação) (Tidd et al., 2005) também são tipicamente formalizadas em planos, resultantes de processos de planejamento mais ou menos detalhados. Por sua vez, estes planos estruturam, integram e coordenam conjuntamente as metas fundamentais das empresas (big questions), suas decisões de nível superior e as metas intermediárias (Morroni, 2006; Rumelt et al., 1991).

Dependendo da complexidade e da abrangência, as estratégias (e os respectivos planos) podem ser subdivididos em subplanos parciais, relativamente específicos (Whittington, 2001; Mintzberg et al. 2006). Frequentemente, as empresas adotam, em relação às estratégias, um comportamento adaptativo (ou sequential aiming), que pode ser descrito como um processo dinâmico de ajustes retroativos de metas intermediárias, a partir de novas informações e dos conhecimentos obtidos na própria organização ou no ambiente econômico - ai incluído os concorrentes. (Morroni, 2006; Simon, 1986).

\footnotetext{
${ }^{2}$ Tradução adaptada. No original, "[s]trategy, one might say, is decision making that deals with the "Big Questions"” (Simon, 1993: 131).

Muito embora as semelhanças sejam significativas, essa definição difere de estratégia proposta por Chandler (1991), dado que parte dela Simon (1986) trata como problem-solving.
} 
Este processo consiste no exame sucessivo dos objetivos parciais, que viabiliza a implementação da tomada de decisão adaptativa e sequencial. Tal procedimento é efetuado com base nos feedbacks de desempenho, resultantes do processo de tentativa e erro (Morroni, 2006; Simon, 1986 e 1983; Cyert e March, 1992).

Os objetivos destes processos são aperfeiçoar as estratégias, reduzir os seus custos e o tempo envolvido nos ajustes retroativos, isto é, ampliar o grau de flexibilidade das estratégias e dos procedimentos de implementação, bem como evitar o comprometimento prematuro com uma estratégia e com o seu respectivo processo de implantação (Morroni, 2006; Simon, 1986 e 1983; Cyert e March, 1992; Vercelli, 1991).

\section{Taxonomias de estratégias de inovação}

O recurso às tipologias é utilizado na análise das estratégias com a finalidade de agrupá-las em categorias específicas, tornando possível algum nível de sistematização, de forma a viabilizar análises de estratégias setoriais a partir de estratégias empresariais. O processo de competição entre as firmas no mercado é capaz de criar uma dinâmica de interação entre elas de forma que estratégias bem-sucedidas possam ser imitadas, enquanto as malsucedidas tornam-se gradativamente em desuso. Este processo de seleção pelo mercado (Nelson e Winter, 1982) produz padrões de comportamento entre as firmas, o que permite analisá-las em categorias dentro de um contexto mais geral que é o setorial. Dessa forma, padrões de conduta estratégica em grupos de empresas específicos tanto recebem influência deste contexto como o influenciam, o que torna viáveis análises de estratégia setorial a partir do nível empresarial. Entre as propostas para classificações de estratégias empresariais mais conhecidas, Ansoff (1965) formulou uma tipologia que se tornou bastante conhecida, baseada em quatro estratégias gerais: 1) penetração de mercado; 2) diversificação; 3) desenvolvimento de produto; e 4) desenvolvimento de mercado. Posteriormente, Porter (1980) desenvolveu uma taxonomia concebida a partir de três estratégias genéricas: 1) liderança de custos; 2) diferenciação; e 3) foco. Esta última pode ser desdobrada, por sua vez, em 3 a) foco em custo e em $3 b$ ) foco em diferenciação (Porter, 1980; Mintzberg et al., 2006). Ainda que úteis e muito influentes, estas taxonomias são excessivamente genéricas e, por isso, restritas em termos heurísticos (Nelson e Winter, 1982), face à elevada diversidade de estratégias empresariais existentes.

No âmbito da tradição neo-schumperetiana, a tipologia das estratégias de inovação proposta por Freeman (Freeman e Soete, 1997) adota, como se sabe, seis casos (ou tipos ideais) de estratégias: 1) ofensiva, 2) defensiva, 3) imitativa, 4) dependente, 5) tradicional e 6) oportunista (ou de nicho).

Em tese, nem todas as estratégias concebíveis estão concretamente disponíveis a todo tipo de empresa e a qualquer momento. De fato, características como tamanho da firma, intensidade da concorrência setorial, fontes do conhecimento (Nelson e Winter, 1982; Pavitt 1984 e 1990; Dosi, 1988; Freeman e Soete, 1997), características tecnológicas - oportunidade, apropriabilidade, cumulatividade - e propriedades da base de conhecimento (técnico ou não) influenciam de maneiras diversas as possibilidades de estratégias efetivamente ao alcance das diferentes empresas (Marsilli, 2001; Dosi et al., 1990). Ademais, a adoção de determinada estratégia está condicionada à disponibilidade de recursos internos e/ou capacidade de acessar e absorver conhecimentos externos aos existentes na firma.

Cabe lembrar, ainda, que as estratégias que as empresas estão aptas a adotar são amplamente impactadas pelos seus contextos nacionais - aí incluídos os sistemas nacionais de inovação implementadas pelas firmas - e pelas respectivas políticas econômicas (Freeman e Soete, 1997; Castellacci, 2008).

Em síntese, as qualificações anteriores tornam o espectro de estratégias de inovação (e/ou tecnológicas) bem mais diversificado e matizado do que a própria tipologia permite deduzir inicialmente. A estas considerações deve se acrescentar também as possibilidades de variações das estratégias ao longo do tempo e de combinações de mais de uma estratégia ao mesmo tempo; uma vez que as empresas, especialmente as grandes, são em geral multiprodutos, 
multitecnologias e, com freqüência, multimercados (Freeman e Soete, 1997; Marsilli, 2001; Pavitt e Steinmueller, 2002).

As considerações acima permitem, em primeiro lugar, admitir que o recurso às tipologias possibilita o reconhecimento de padrões de comportamento das empresas que se manifestam no próprio plano das firmas (tipologia de Freeman e Soete, 1997) e, também, no âmbito setorial - taxonomias do Pavitt (1984) e de regimes tecnológicos (Marsilli, 2001) - e, neste sentido, o estudo das estratégias não fica circunscrito aos limites das estratégias empresarias individuais - onde elas se originam -, podendo se beneficiar da emergência de padrões decorrentes dos processos de seleção e imitação (Nelson e Winter, 1982) que operam no plano dos mercados/indústrias. O espaço para as estratégias tecnológicas setoriais viabilizadas por uma agregação conveniente que, por sua vez, advém das próprias sistematizações industriais - é definido, por seu turno, pelas fronteiras do conhecimento técnicocientífico, determinadas, respectivamente, pelas trajetórias de um paradigma (Dosi, 1988) ou pelos regimes tecnológicos (Marsilli, 2001) em vigor. Nestas condições, parece ser possível associar as estratégias tecnológicas às características dos padrões setoriais de inovação, como proposto no item 4.2, a partir da taxonomia de Pavitt $(1984)^{3}$.

Em segundo lugar, ainda considerando a discussão anterior, é cabível supor que as estratégias tecnológicas podem variar significativamente dentro de uma mesma indústria, particularmente no âmbito internacional, em razão das diferenças entre recursos, capacidades e características institucionais. Nestes termos, mesmo diante da impossibilidade de determinar exant qual a estratégia tecnológica é a melhor entre todas as concebíveis, é razoável assumir que quanto mais intenso for o esforço inovativo, maiores são as possibilidades de uma estratégia que acompanha o padrão setorial - vir a ser relativamente bem sucedida.

\section{Estratégias tecnológicas na indústria de transformação brasileira}

O objetivo desta seção é avaliar as estratégias tecnológicas predominantes da indústria de transformação brasileira. Para isso, no primeiro subitem são descritas as bases de dados e os indicadores propostos para a análise no subitem 4.2. Essa análise está sustentada nos seguintes pressupostos: (i) a estratégia setorial segue as estratégias adotadas pelas empresas de uma indústria e variam segundo a tipologia de Freeman e Soete (1997); (ii) as estratégias de inovação podem ser analisadas a partir dos procedimentos inovativos (aqui medidos pelos indicadores de intensidade); (iii) na amostra, a melhor estratégia da indústria é dada pelo mais alto valor da amostra nos indicadores de intensidade que caracterizam o padrão setorial de inovação; (iv) a melhor estratégia tecnológica é aquela que segue o padrão inovativo esperado para a indústria (Pavitt, 1984) ${ }^{4}$. Se os três primeiros itens sustentam a análise decorrente dos indicadores, o quarto permite confrontar esses resultados com a trajetória tecnológica setorial (estratégia esperada).

\subsection{Descrição da base de dados e dos indicadores}

O objetivo desta seção é avaliar as estratégias tecnológicas adotadas na indústria de transformação brasileira. Para isso, incialmente são calculados os indicadores de intensidade tecnologia em 19 setores da indústria brasileira e de 12 países europeus ${ }^{5}$. Os dados para o Brasil

\footnotetext{
3 Por exemplo, os setores que seguem o padrão baseado em ciência devem ser dominados pelas estratégias ofensivas, defensivas, de imitação ou até mesmo dependentes, mas deixando pouco espaço para a adoção de estratégias tradicionais. Todavia, os padrões setoriais de inovação podem ou não ser assimilados ou adotados como estratégia de inovação (competitiva) empresarial. Em tese, cada padrão da primeira tipologia pode comportar diferentes estratégias da segunda.

${ }^{4}$ As propostas para essas relações são apresentadas nos quadros 1 a 4 do item 4.2.

5 Alemanha, Áustria, Croácia, Eslováquia, Finlândia, Grécia, Hungria, Itália, Macedônia, Noruega, Portugal e Sérvia.
} 
foram obtidos da Pesquisa de Inovação Tecnológica - PINTEC (2014), elaborada pelo IBGE -, e as informações para os países europeus foram retiradas da Community Innovation Survey - CIS (2016), disponibilizadas pelo European Statistics System.

O trabalho de Campos e Ruiz (2009) foi utilizado como referência metodológica para os padrões setoriais de inovação na indústria brasileira, compatíveis com a taxonomia proposta por Pavitt (1984), assim como os indicadores de inovação e de imitação de produto e de processo. De forma análoga a este estudo, é possível obter o foco da estratégia tecnológica de cada setor. Para o Brasil, a partir dos dados da PINTEC relativos à proporção de empresas que considera de alto impacto a introdução de inovações para melhoria da qualidade dos produtos (foco em produto - Foco $_{\text {prod }}$ ) ou redução dos custos de produção (foco em processo - Foco proc $_{\text {) }}$ ).

Em relação aos dados dos países europeus (CIS), o foco da estratégia tecnológica dos setores foi obtido considerando-se a proporção de empresas que introduziram inovações para a melhoria de bens e serviços existentes (foco em produto - Foco prod) ou na redução de preços (foco em inovação de processo - Foco proc $_{\text {). }}$.

Os indicadores de intensidade em imitação ou inovação de processo e produto são descritos abaixo:

- Intensidade em imitação de processo $\left(\right.$ Processo $\left._{I m}\right)$ - Soma dos Gastos com aquisição de $\mathrm{P} \& \mathrm{D}$ externo e outros conhecimentos externos ${ }^{6}$ como proporção do faturamento do setor $\left(P \& D_{\text {ext }}\right)$ e Gasto com aquisição de outros conhecimentos externos como proporção do faturamento das empresas $\left(O C_{\text {ext }}\right)$, ponderada pelo foco da trajetória tecnológica em processo $\left(\right.$ Foco $\left._{\text {proc }}\right)$.

$$
\text { Processo }_{\text {Im }}=\left(P \& D_{\text {ext }}+O C_{\text {ext }}\right) * \frac{\text { Foco }_{\text {proc }}}{\text { Foco }_{\text {proc }}+\text { Foco }_{\text {prod }}}
$$

- Intensidade em inovação de processo $\left(\right.$ Processo $\left._{I n}\right)$ - Gasto com aquisição de $\mathrm{P} \& \mathrm{D}$ interno como proporção do faturamento do setor $\left(P \& D_{\text {int }}\right)$, ponderado pelo foco da trajetória tecnológica em processo $\left(\right.$ Foco $\left._{\text {proc }}\right)$.

$$
\text { Processo }_{\text {In }}=\left(P \& D_{\text {int }}\right) * \frac{\text { Foco }_{\text {proc }}}{\text { Foco proc }_{\text {Foco }} \text { prod }}
$$

- Intensidade em imitação de produto $\left(\right.$ Produto $\left._{I m}\right)$ - Soma dos Gastos com aquisição de $\mathrm{P} \& \mathrm{D}$ externo e outros conhecimentos externos como proporção do faturamento do setor $\left(P \& D_{\text {ext }}\right)$ e Gasto com aquisição de outros conhecimentos externos como proporção do faturamento das empresas $\left(O C_{\text {ext }}\right)$, ponderada pelo foco da trajetória tecnológica em produto (Foco prod $)$.

$$
\text { Produto }_{I m}=\left(P \& D_{\text {ext }}+O C_{\text {ext }}\right) * \frac{\text { Foco }_{\text {prod }}}{\text { Foco }_{\text {proc }}+\text { Foco }_{\text {prod }}}
$$

- Intensidade em inovação de produto $\left(\right.$ Produto $\left._{I n}\right)$ - Gasto com aquisição de P\&D interno como proporção do faturamento do setor $\left(P \& D_{\text {int }}\right)$ ponderado pelo foco da trajetória tecnológica em produto $\left(\right.$ Foco $\left._{\text {prod }}\right)$.

$$
\text { Produto }_{\text {In }}=\left(P \& D_{\text {int }}\right) * \frac{\text { Foco }_{\text {prod }}}{\text { Foco }_{\text {proc }}+\text { Foco }_{\text {prod }}}
$$

Intensidade em inovações organizacionais e de marketing - Número de empresas que realizaram inovações organizacionais e de marketing em relação ao total de empresas investigadas em cada setor industrial.

\footnotetext{
6 Segundo as notas metodológicas da PINTEC para preenchimento do questionário (IBGE, 2012), o termo "Aquisição de outros conhecimentos externos" compreende os acordos de transferência de tecnologia originados da compra de licença de direitos de exploração de patentes e uso de marcas, aquisição de know-how e outros tipos de conhecimentos técnico-científicos de terceiros. "A diferença entre aquisição externa de $\mathrm{P} \& \mathrm{D}$ e aquisição de outros conhecimentos externos é que, no primeiro, uma pessoa/instituição é contratada para desenvolver o P\&D ou uma parte deste e no segundo, a empresa adquire um conhecimento previamente desenvolvido." (IBGE, 2012, p. 16). Tanto o caso de aquisição de $\mathrm{P} \& \mathrm{D}$ externo como aquisição de outros conhecimentos externos, a empresa não desenvolve atividades inovativas utilizando capacitações que lhe são próprias, portanto referem-se a situações em que a empresa adquire um conhecimento externo e, portanto, estão associados a um padrão de imitação.
} 


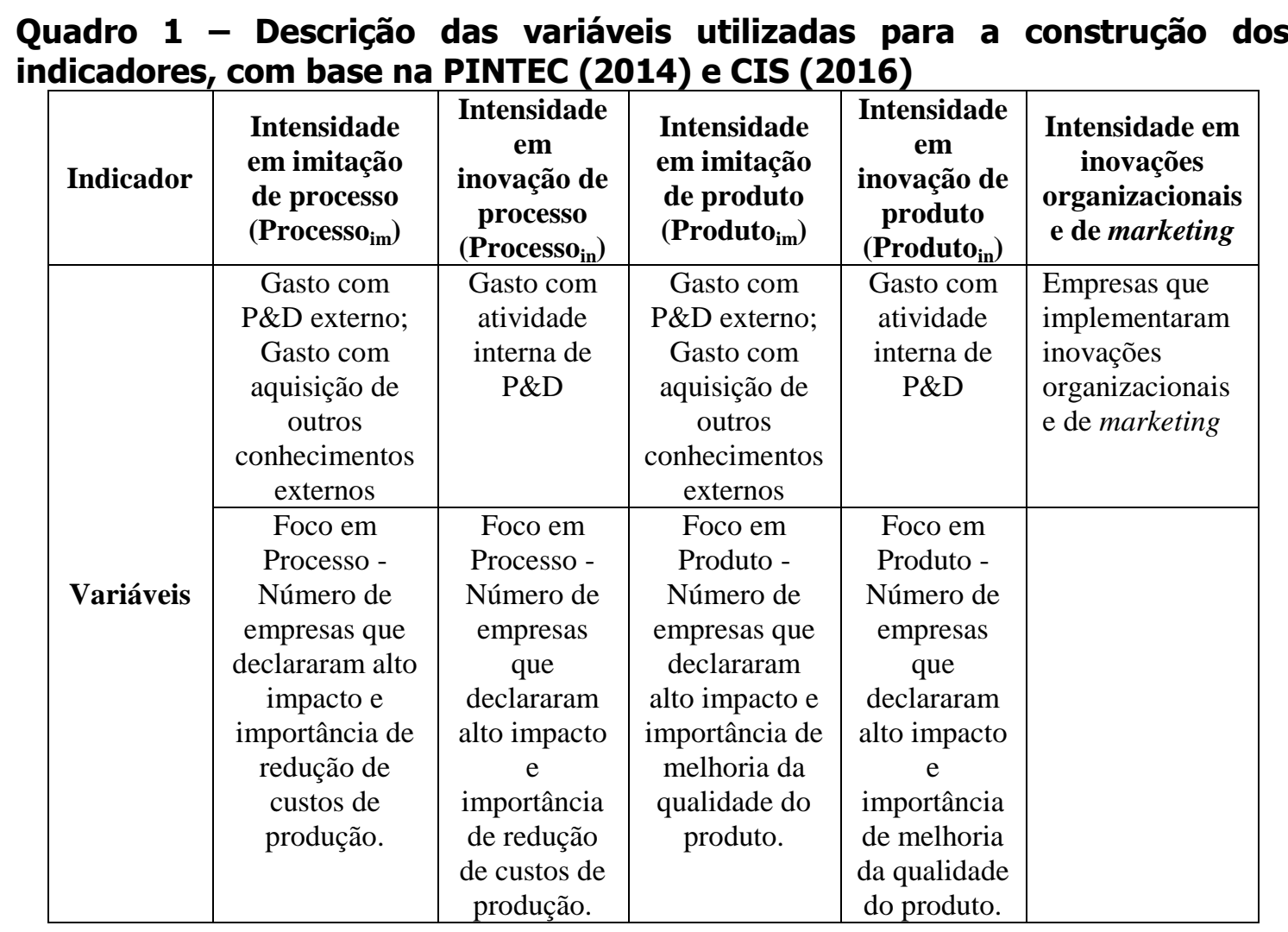

Para este estudo, os 19 setores industriais investigados foram agrupados, para efeitos de apresentação, segundo o critério de intensidade tecnológica proposto pela OCDE: setores de baixa intensidade tecnológica, média baixa e média alta intensidade tecnológica e alta intensidade tecnológica ${ }^{7}$. Em relação aos países, não há, infelizmente, uma homogeneidade na amostra das nações europeias, uma vez que alguns países que responderam os questionários da CIS não disponibilizaram informações para todos os setores industriais, comprometendo, assim, a possibilidade da construção totalmente uniforme dos indicadores analisados neste artigo. Em setores como Fabricação de bebidas, por exemplo, somente Alemanha, Áustria e Sérvia divulgaram dados que viabilizam a construção dos indicadores. Os resultados dos indicadores de intensidade são apresentados nas tabelas 1 a 4.

O segundo passo da metodologia - após terem sido selecionados os melhores desempenhos de cada indicador de intensidade (estratégias de referência) e considerando o padrão setorial (tipos predominantes de atividades inovativas) proposto por Pavit (1984) - é sistematizar as estratégias setoriais brasileiras. Os quadros 1 a 4 resumem essa avaliação.

\subsection{Resultados}

As tabelas 1 a 4 apresentam os cinco indicadores de intensidade propostos para este estudo segundo as quatro categorias de intensidade tecnológica. Para cada setor, os dados estão

\footnotetext{
${ }^{7}$ Setores de baixa intensidade tecnológica: 1) Fabricação de alimentos; 2) Fabricação de bebidas; 3) Fabricação de produtos têxteis; 4) Confecção de artigos de vestuário; 5) Confecção de artigos de couro e calçados; 6) Fabricação de papel, celulose e produtos de papel; 7) Fabricação de Móveis; 8) Fabricação de produtos manufaturados diversos. Setores de média baixa intensidade tecnológica: 1) Fabricação de borracha e produtos plásticos; 2) Fabricação de minerais não-metálicos; 3) Metalurgia; 4) Fabricação de produtos de metal. Setores de média alta intensidade tecnológica: 1) Fabricação de produtos químicos; 2) Fabricação de máquinas, aparelhos e materiais elétricos; 3) Fabricação de máquinas e equipamentos; 4) Fabricação de veículos e autopeças. Setores de alta intensidade tecnológica: 1) Fabricação de produtos farmacêuticos; 2) Fabricação de equipamentos de informática, eletrônicos e ópticos; 3) Fabricação de outros equipamentos de transporte.
} 
dispostos de forma a comparar o desempenho do Brasil em cada indicador com o país mais bem posicionado na amostra. Adicionalmente, são destacados (proporção) os indicadores brasileiros que obtiveram comportamento Baixo (até $40 \%$ do maior valor), Médio Baixo ( $+40 \%$ a $60 \%$ ), Médio Alto (+60\% a $80 \%)$ e Alto $(+80 \%)$. A partir desses resultados, considerados em conjunto com as características setoriais, são avaliadas as estratégias tecnológicas setoriais segundo a tipologia de Freeman e Soete (1997) ${ }^{8}$.

Segundo o Manual de Oslo (2005), novos métodos de marketing contemplam tanto alterações expressivas no conceito de um produto já existente, incluindo a embalagem, o reposicionamento de um produto no mercado, as políticas de preços, ou a abertura de novos mercados - em geral, são inovações voltadas a promoção das vendas. Ainda de acordo com o Manual, as inovações organizacionais incorporam novos métodos organizacionais - desde o (re)direcionamento de responsabilidades e de decisões, até novos métodos que alteram os processos, as rotinas e o relacionamento com os fornecedores. Como mostram as tabelas 1 a 4 , coluna 5, esta é a atividade inovativa comum, mais intensa nos setores industriais brasileiros e, quase sempre, com resultados superiores aos apresentados pelos países europeus. Esta circunstância, associado aos resultados gerais (comentados a seguir), parece apontar para uma economia pouco voltada à inovação e a imitação - em particular, às estratégias empresariais ofensiva ou defensiva - e mais voltada para ajustes (reposicionamentos) e esforços de vendas, dadas as desvantagens nas capacitações e nas estratégias inovativas prevalecentes - imitativa, dependente, tradicional e, eventualmente, de nicho, quando esta prescinde de conteúdo técnico mais sofisticado.

A tabela 1 apresenta os cinco indicadores de intensidade aplicados aos setores de baixa intensidade tecnológica. A indústria de alimentos, que se caracteriza pela diversidade de tamanho, foi classificada por Pavitt (1984) como intensiva em produção. Neste contexto, o desenvolvimento tecnológico setorial ocorre por meio inovações de produto e, principalmente, de marketing (levadas a cabo pelas líderes e enfatizando a diferenciação de produtos e a marca) - imitadas pelas demais - e mudanças organizacionais em resposta, especialmente, às inovações em processo - desenvolvidos internamente, mas principalmente por fornecedores especializado. Os indicadores de imitação de processo e produto para o Brasil foram de, respectivamente, $(0,02 \%)$ e $(0,03 \%)$. Em contrapartida, a Sérvia - que têm adotado uma estratégia de realização de significativos esforços em imitação de processo e de produto - apresentou, por sua vez, indicadores de $(0,62 \%)$ no primeiro caso e de $(1,67 \%)$ no último. Entre os países europeus da amostra, a Sérvia foi o país que implementou os maiores esforços de imitação. Por outro lado, a Noruega apresentou o maior indicador para inovação de processo $(0,25 \%)$ e a Finlândia liderou os esforços de inovação de produto $(0,49 \%)$, respectivamente.

Em suma, assim como para outras três indústrias brasileiras da mesma categoria Produtos Têxteis, Artigos de Vestuário (setores que a introdução/imitação de novos produtos constituiu-se como a estratégia principal para manter fatias de mercado ou para conquistar novos mercados) e Produtos Diversos -, os indicadores reduzidos de intensidade de Fabricação de Alimentos, relativamente ao melhores desempenhos, parecem indicar que as estratégias tecnológicas adotadas pelas empresas brasileiras não são compatíveis com o padrão setorial.

A posição relativa do Brasil no indicador de introdução de inovação de produto é comparável ao melhor desempenho em apenas três dos oito setores de baixa intensidade tecnológica: Bebidas $(0,05 \%)$, igual ao desempenho da Áustria, Couro $(0,52 \%)$, superado apenas pela Alemanha $(1,09 \%)$ e Fabricação de Móveis $(0,30 \%)$, pouco abaixo dos cerca de $40 \%$ da Áustria (vide Tabela 1). Neste mesmo conjunto, a habilidade de introduzir inovações de processo é marcada, por sua vez, por duas performances diferenciadas - Bebidas, que apresentou o melhor indicador da amostra $(0,04 \%)$, e Couro e Calçados, que alcançou $83 \%$ do esforço da Alemanha $(0,23 \%)$. Ressalta-se, como esperado, os valores reduzidos de todos os indicadores, nacionais e europeus, desta classificação em comparação com as demais.

\footnotetext{
${ }^{8}$ Nessas tabelas estão negritados os indicadores brasileiros que alcançam uma proporção ao menos mediana em relação ao melhor desempenho.
} 
Tabela 1 - Indicadores de intensidade em imitação e inovação por setores de baixa intensidade tecnológica - Brasil e país com melhor desempenho no indicador

\begin{tabular}{|c|c|c|c|c|c|c|c|c|c|c|}
\hline & \multicolumn{4}{|c|}{ Processo } & \multicolumn{4}{|c|}{ Produto } & \multirow{2}{*}{\multicolumn{2}{|c|}{$\begin{array}{c}\text { Inovações } \\
\text { Organizacionais } \\
\text { e de Marketing }\end{array}$}} \\
\hline & \multicolumn{2}{|c|}{ Imitação } & \multicolumn{2}{|c|}{ Inovação } & \multicolumn{2}{|c|}{ Imitação } & \multicolumn{2}{|c|}{ Inovação } & & \\
\hline \multicolumn{11}{|c|}{ Fabricação de Alimentos } \\
\hline Brasil & & 0,02 & & 0,05 & & 0,03 & & 0,09 & & 27,38 \\
\hline Líder & Sérvia & 0,62 & Noruega & 0,25 & Sérvia & 1,67 & Finlândia & 0,49 & Brasil & 27,38 \\
\hline Class (\%) & $\mathrm{B}$ & 3,2 & $\mathrm{~B}$ & 20,0 & $\mathrm{~B}$ & 1,8 & $\mathrm{~B}$ & 18,4 & $\mathrm{~A}$ & 100,0 \\
\hline \multicolumn{11}{|c|}{ Fabricação de bebidas } \\
\hline Brasil & & 0,02 & & 0,04 & & 0,02 & & 0,05 & & 45,33 \\
\hline Líder & Sérvia & 0,08 & Brasil & 0,04 & Sérvia & 0,56 & Áustria & 0,05 & Brasil & 45,33 \\
\hline Class (\%) & $\mathrm{B}$ & 25,0 & A & 100,0 & & 3,6 & A & 100,0 & A & 100,0 \\
\hline \multicolumn{11}{|c|}{ Fabricação de Produto Têxteis } \\
\hline Brasil & & 0,03 & & 0,05 & & 0,06 & & 0,09 & & 34,71 \\
\hline Líder & Noruega & 0,12 & Noruega & 0,64 & Áustria & 0,14 & Itália & 0,85 & Brasil & 34,71 \\
\hline Class (\%) & $\mathrm{B}$ & 25,0 & $\mathrm{~B}$ & 7,8 & MB & 42,9 & $\mathrm{~B}$ & 10,6 & A & 100,0 \\
\hline \multicolumn{11}{|c|}{ Fabricação de Artigos e Vestuário } \\
\hline Brasil & & 0,01 & & 0,08 & & 0,03 & & 0,14 & & 39,69 \\
\hline Líder & Itália & 0,08 & Itália & 0,31 & Itália & 0,34 & Itália & 1,32 & Brasil & 39,69 \\
\hline Class (\%) & $\mathrm{B}$ & 12,5 & $\mathrm{~B}$ & 25,8 & $\mathrm{~B}$ & 8,8 & $\mathrm{~B}$ & 10,6 & A & 100,0 \\
\hline \multicolumn{11}{|c|}{ Fabricação de Artigos Couros e Calçados } \\
\hline Brasil & & 0,03 & & 0,19 & & 0,07 & & 0,52 & & 46,37 \\
\hline Líder & Sérvia & 0,27 & Alemanha & 0,23 & Sérvia & 0,72 & Alemanha & 1,09 & Brasil & 46,37 \\
\hline Class (\%) & $\mathrm{B}$ & 11,1 & A & 82,6 & $\mathrm{~B}$ & 9,7 & $\mathrm{M}$ & 47,7 & A & 100,0 \\
\hline \multicolumn{11}{|c|}{ Fabricação de Papel, Celulose e Produtos de Papel } \\
\hline Brasil & & 0,03 & & 0,24 & & 0,02 & & 0,16 & & 38,67 \\
\hline Líder & Noruega & 0,05 & Brasil & 0,24 & Itália & 0,20 & Finlândia & 0,46 & Finlândia & 43,84 \\
\hline Class (\%) & MB & 60,0 & A & 100,0 & $\mathrm{~B}$ & 10,0 & B & 34,8 & A & 88,2 \\
\hline \multicolumn{11}{|c|}{ Fabricação de Móveis } \\
\hline Brasil & & 0,04 & & 0,15 & & 0,09 & & 0,30 & & 39,71 \\
\hline Líder & Croácia & 0,06 & Noruega & 0,70 & Croácia & 0,19 & Áustria & 0,71 & Brasil & 39,71 \\
\hline Class (\%) & MA & 66,7 & $\mathrm{~B}$ & 21,4 & $\mathrm{M}$ & 47,4 & MB & 42,3 & $\mathrm{~A}$ & 100,0 \\
\hline \multicolumn{11}{|c|}{ Fabricação de Produtos Diversos } \\
\hline Brasil & & 0,05 & & 0,21 & & 0,08 & & 0,35 & & 32,37 \\
\hline Líder & Noruega & 0,67 & Noruega & 1,52 & Noruega & 0,67 & Áustria & 5,87 & Sérvia & 36,23 \\
\hline Class (\%) & $\mathrm{B}$ & 7,5 & $\mathrm{~B}$ & 13,8 & $\mathrm{~B}$ & 11,9 & $\mathrm{~B}$ & 6,0 & A & 89,3 \\
\hline
\end{tabular}

Fonte: Elaboração própria a partir de CIS (2016) e PINTEC (2014)

Obs. Class (Classificação): Médio baixo (MB); Médio Alto (MA); Alto (A); Baixo (B)

Em relação à habilidade de introduzir inovações de processo, o Brasil apresentou resultados também expressivos no setor de Fabricação de Papel e Celulose $(0,24 \%)$, assumindo a liderança entre os países analisados. Para esse setor, o indicador de imitação de produtos $(0,02 \%)$ desenvolvidos pelos concorrentes não se tornou a estratégia principal, sendo apenas uma atividade medianamente desenvolvida. A Noruega, com $(0,05 \%)$, foi a nação com melhor desempenho neste caso.

O grupo das indústrias de baixa intensidade tecnológica é classificado em Freeman e Soete (1997) dentre os setores com predominância de estratégias defensivas, imitativas e tradicionais; embora algumas empresas possuam recursos e habilidades para inovar, preferem evitar as incertezas dos primeiros lançamentos. Dessa forma, apostam na própria capacidade de aperfeiçoar/imitar as versões iniciais das inovações introduzidas pelos poucos adversários ofensivos. Em relação aos padrões setoriais de inovação, esta estratégia é compatível com setores dominados por fornecedores e intensivos em produção, seja pela fraca capacitação própria em engenharia e em $\mathrm{P} \& \mathrm{D}$, seja por trajetórias tecnológicas definidas pela redução de custos e por diferenciais competitivos baseados em marcas e propaganda. 
Na maioria dos setores brasileiros de baixa tecnologia, há predomínio das estratégias dependentes, característica de empresas que desempenham o papel subordinado ou dependente de outras empresas, como, por exemplo, certas filiais de multinacionais e empresas subcontratadas, como é o caso do setor de alimentos no Brasil. Mesmo não destinando elevados recursos para a realização de atividades de $\mathrm{P} \& \mathrm{D}$, as empresas destes setores possuem alguma capacidade para o desenvolvimento de atividades imitativas com vistas à diferenciação de produtos e a melhorias de processos.

Algumas situações atípicas encontradas na indústria brasileira são observadas nos setores de Fabricação de Bebidas e Fabricação de Papel e Celulose. Em ambos os casos, os indicadores setoriais revelam o uso de estratégias ofensivas por parte das empresas. As estratégias inovativas ofensivas, segundo Freeman e Soete (1997), são típicas de situações em que as posições relativas dos líderes e dos seguidores são bastante mutáveis e boa parte do conhecimento para inovar é interno à firma, tornando a capacidade para introduzir inovações de produto e processo especialmente relevante para ameaçar as posições de mercado das concorrentes. No caso da indústria brasileira, os indicadores de intensidade tecnológica em inovações de produto e de processo, relativamente elevados, caracterizam estes dois setores, indicando que as empresas têm uma relativamente forte preocupação em competir por novas fatias de mercado, desenvolvendo para tal capacitações tecnológicas acima da média nacional.

As estratégias para as indústrias brasileiras de baixa intensidade tecnologia estão sistematizadas no quadro 2.

\begin{tabular}{|c|c|c|c|}
\hline Baixa Tecnologia & $\begin{array}{l}\text { Padrões setoriais de } \\
\text { Inovação } \\
\text { (Pavitt, 1984) }\end{array}$ & $\begin{array}{c}\text { Estratégias de } \\
\text { Inovação } \\
\text { (Freeman e Soete, } \\
\text { 1997) }\end{array}$ & $\begin{array}{c}\text { Resultados do } \\
\text { Estudo para Brasil }\end{array}$ \\
\hline Fabricação de Alimentos & Intensivo em escala & Defensiva/Imitativa & Dependente \\
\hline Fabricação de bebidas & Intensivo em escala & Defensiva/Imitativa & Ofensiva (Processos) \\
\hline Fabricação de Produto Têxteis & Dominado pelo fornecedor & Defensiva/Imitativa & Dependente \\
\hline Fab. Artigos e Vestuário & Dominado pelo fornecedor & Defensiva/Imitativa & Dependente \\
\hline Fab. Artigos Couros e Calçados & Dominado pelo fornecedor & Defensiva/Imitativa & Imitativa \\
\hline Fab. Papel, Celulose e Prod Papel & Intensivo em escala & Defensiva/Imitativa & Ofensiva (Processos) \\
\hline Fabricação de Móveis & Dominado pelo fornecedor & Defensiva/Imitativa & Imitativa \\
\hline Fabricacão de Produtos Diversos & Fornecedor especializado & Defensiva/Imitativa & Dependente \\
\hline
\end{tabular}

Fonte: Elaboração própria, com base nos resultados da pesquisa.

A tabela 2 apresenta os resultados dos indicadores de intensidade em imitação de produto e de processo, em inovação de produto e de processo e em inovação organizacional e de marketing, para os setores de média baixa intensidade tecnológica. No setor de Fabricação de Plásticos e de Produtos Plásticos, as evidências para o Brasil demostram uma clara estratégia imitativa. O indicador de intensidade em inovação de processo do Brasil foi de $(0,08 \%)$, ocupando a segunda posição, atrás, apenas, da Noruega (0,13\%). Diferentemente dos casos apresentados nos setores de baixa intensidade tecnológica, aqui a distância entre o Brasil e o países com melhor desempenho não foi tão significativa. A estratégia imitativa também ficou evidente no caso de produto. $\mathrm{O}$ indicador de intensidade em imitação de produto para o Brasil $(0,18 \%)$ mostrou-se inferior somente ao da Áustria $(0,27 \%)$.

Ainda que a habilidade brasileira para introduzir inovações - de produto ou de processo tenha se mostrado muito abaixo dos países mais bem posicionados nestes setores, o Brasil demonstrou uma estratégia clara de imitação para alcançar os países líderes na introdução de inovações. Para o indicador de intensidade em inovação de produto, o resultado para o Brasil foi de apenas $(0,33 \%)$, enquanto a Áustria, país que ocupou a primeira posição neste caso, apresentou esforço de $(2,09 \%)$. 
Nos setores de Fabricação de Minerais Não-metálicos e Metalurgia, os resultados dos indicadores de intensidade em inovação de processo, quando comparados com o país melhor posicionado, mostram um desempenho brasileiro médio baixo (MB). Esses dois últimos setores são classificados, segundo a taxonomia proposta por Pavitt (1984), como dominados por fornecedores - em função da maturidade tecnológica que caracterizam estas atividades-, fazendo com que as respectivas trajetórias tecnológicas sejam definidas por redução de custos. Neste sentido, os esforços do Brasil na introdução de inovações de processo estão aparentemente alinhados com as características tecnológicas da indústria internacional.

Tabela 2 - Indicadores de intensidade em imitação e inovação por setores de média baixa intensidade tecnológica - Brasil e país com melhor desempenho no indicador

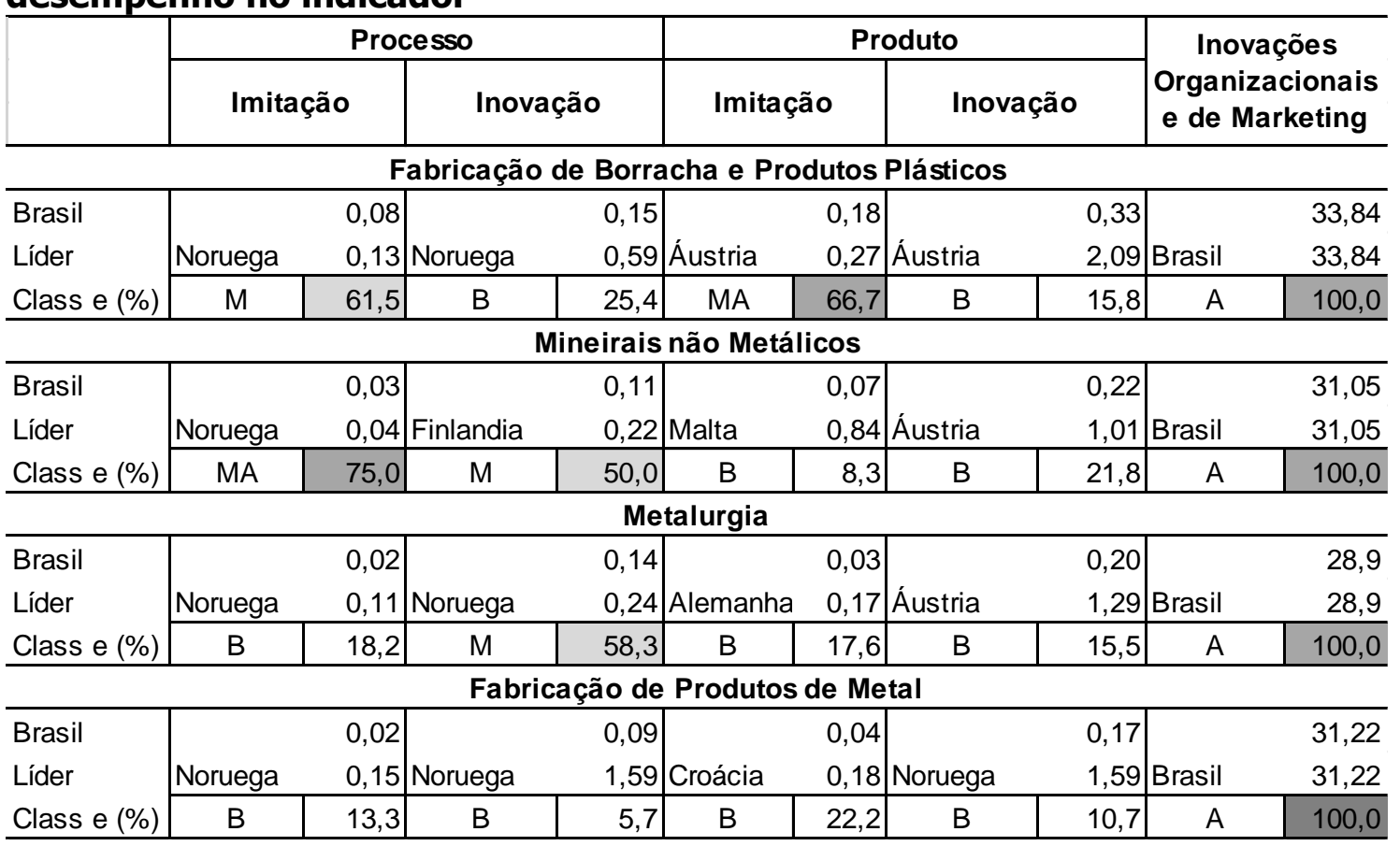

Fonte: Elaboração própria a partir de CIS (2016) e PINTEC (2014)

Obs. Class (Classificação): Médio baixo (MB); Médio Alto (MA); Alto (A); Baixo (B)

As características tecnológicas dos setores investigados na tabela 2 permitem classificar suas estratégias inovativas, seguindo a proposta de Freeman e Soete (1997), como predominantemente Defensivas. O grau de maturidade tecnológica das indústrias dificulta mudanças bruscas de posições de mercado entre as empresas, o que torna a competição mais intensiva em redução de custos. A estratégia defensiva caracteriza estas atividades pelo alto desempenho dos setores europeus nos indicadores de inovação e imitação, revelando que as empresas nestes setores possuem capacitações para imitar e inovar. No caso brasileiro, somente a indústria de Fabricação de Borracha e Produtos Plásticos demonstra capacitação para adotar uma estratégia imitativa, que difere da estratégia Defensiva pelo fato de não apresentar bom desempenho nos indicadores de inovação. Nos demais setores de média baixa tecnologia, o Brasil adota a estratégia Tradicional, em que as empresas não desenvolvem inovações tecnológicas expressivas, e as melhorias de processos são resultantes dos bens de capital adquiridos e disponíveis no mercado por fornecedores especializados.

O quadro 3 sistematiza as estratégias de inovação a partir do desempenho dos indicadores observados na tabela 2. 


\begin{tabular}{|c|c|c|c|}
\hline Média Baixa Tecnologia & $\begin{array}{l}\text { Padrões setoriais de } \\
\text { Inovação } \\
\text { (Pavitt, 1984) }\end{array}$ & $\begin{array}{c}\text { Estratégias de } \\
\text { Inovação } \\
\text { (Freeman e Soete, } \\
\text { 1997) } \\
\end{array}$ & $\begin{array}{c}\text { Resultados do } \\
\text { Estudo para Brasil }\end{array}$ \\
\hline Fab. Borracha e Prod. Plásticos & Intensivo em produção & Defensiva & Imitativa \\
\hline Mineirais não Metálicos & Dominado pelo fornecedor & Defensiva & Tradicional \\
\hline Metalurgia & Dominado pelo fornecedor & Defensiva & Tradiconal \\
\hline Fab. Borracha e Prod. Plásticos & Intensivo em produção & Defensiva & Imitativa \\
\hline
\end{tabular}

Fonte: Elaboração própria, com base nos resultados da pesquisa.

Na tabela 3, abaixo, são apresentados os cinco indicadores calculados para os setores de média alta intensidade tecnológica. Nesse grupo, o Brasil possui baixa capacidade de imitar e inovar, tanto em produto quanto em processo. A única ressalva a ser mencionada são as das atividades inovativas organizacionais e de marketing, para os quais os valores obtidos são elevados para o Brasil e também para os países europeus - diferentemente das indústria discutidas anteriormente.

\begin{tabular}{|c|c|c|c|c|c|c|c|c|c|c|}
\hline & \multicolumn{4}{|c|}{ Processo } & \multicolumn{4}{|c|}{ Produto } & \multirow{2}{*}{\multicolumn{2}{|c|}{$\begin{array}{c}\text { Inovações } \\
\text { Organizacionais } \\
\text { e de Marketing }\end{array}$}} \\
\hline & \multicolumn{2}{|c|}{ Imitação } & \multicolumn{2}{|c|}{ Inovação } & \multicolumn{2}{|c|}{ Imitação } & \multicolumn{2}{|c|}{ Inovação } & & \\
\hline \multicolumn{11}{|c|}{ Fabricação de Produtos Químicos } \\
\hline Brasil & & 0,09 & & 0,24 & & 0,19 & & 0,51 & & 23,30 \\
\hline Líder & Noruega & $0,40 \mid$ & Noruega & 0,85 & Alemanha & 0,43 & Alemanha & 2,29 & Finlândia & 35,04 \\
\hline Class e (\%) & $\mathrm{B}$ & 22,5 & $\mathrm{~B}$ & 28,2 & MB & 44,2 & $\mathrm{~B}$ & 22,3 & MA & 66,5 \\
\hline \multicolumn{11}{|c|}{ Fabricação de Máquinas Aparelhos e Materiais Elètricos } \\
\hline Brasil & & 0,04 & & 0,7 & & 0,06 & & 1,13 & & 22,48 \\
\hline Líder & Sérvia & $0,24 \mid \mathrm{F}$ & Finlândia & 1,66 & Alemanha & 0,66 & Alemanha & 4,80 & Finlândia & 33,78 \\
\hline Class e (\%) & $\mathrm{B}$ & 16,7 & $\mathrm{~B}$ & 42,2 & $\mathrm{~B}$ & 9,1 & $\mathrm{~B}$ & 23,5 & MA & 66,5 \\
\hline \multicolumn{11}{|c|}{ Fabricação de Máquinas e Equipamentos } \\
\hline Brasil & & 0,03 & & 0,24 & & 0,07 & & 0,55 & & 33,26 \\
\hline Líder & Noruega & $0,12 \mid r$ & Noruega & 0,99 & Alemanha & 0,55 & Áustria & 3,91 & Sérvia & 38,31 \\
\hline Class e $(\%)$ & $\mathrm{B}$ & 25,0 & $\mathrm{~B}$ & 24,2 & $\mathrm{~B}$ & 12,7 & $\mathrm{~B}$ & 14,1 & A & 86,8 \\
\hline \multicolumn{11}{|c|}{ Fabricação de Veículos e Autopeças } \\
\hline Brasil & & 0,06 & & 0,30 & & 0,15 & & 0,80 & & 41,16 \\
\hline Líder & Noruega & $0,34 \mid N$ & Noruega & 1,66 & Alemanha & 1,06 & Alemanha & 3,94 & Brasil & 41,16 \\
\hline Class e (\%) & $\mathrm{B}$ & 17,6 & $\mathrm{~B}$ & 18,1 & $\mathrm{~B}$ & 14,2 & $\mathrm{~B}$ & 20,3 & $A$ & 100,0 \\
\hline
\end{tabular}

Fonte: Elaboração própria a partir de CIS (2016) e PINTEC (2014)

Obs. Class (Classificação): Médio baixo (MB); Médio Alto (MA); Alto (A); Baixo (B)

No grupo de setores de média alta tecnologia, grande parte das empresas são filiais de multinacionais estrangeiras e seguem as estratégias tecnológicas determinadas pelas matrizes. No Brasil, o baixo desempenho observado nos indicadores de inovação e imitação demonstra que o Brasil não desenvolve fortes capacitações para a realização de $\mathrm{P} \& \mathrm{D}$. Este fato, aliado à forte presença de empresas multinacionais nestes setores, reforça a caracterização da estratégia inovativa como Dependente, conforme sistematizado no quadro 3.

Em relação aos padrões setoriais de inovação, exceto o setor de Fabricação de Máquinas e Equipamentos (fornecedor especializado), os demais são intensivos em produção. Neste caso, a necessidade de aproveitar ao máximo as economias de escala é predominante nestes setores, 
fazendo com que as inovações de processo sejam mais relevantes que as de produto. Os indicadores de inovação analisados para o conjunto de países europeus investigados mostram que aqueles que ocupam posições de destaque em relação ao desempenho tecnológico não apenas adotam estratégias ofensivas em relação a inovação de processo, mas também em relação a inovação de produto. A Alemanha, conforme observado na tabela 3, lidera os indicadores de intensidade em inovação de produto na maioria dos setores de média alta tecnologia. No caso brasileiro, diferente do padrão europeu, ao contrário da estratégia inovativa ofensiva o que se observa é um padrão estratégico reativo, em que as mudanças de processo dependem de solicitações de clientes ou das matrizes estrangeiras.

\begin{tabular}{|c|c|c|c|}
\hline Média Alta Tecnologia & $\begin{array}{l}\text { Padrões setoriais de } \\
\text { Inovação } \\
\text { (Pavitt, 1984) }\end{array}$ & $\begin{array}{c}\text { Estratégias de } \\
\text { Inovação } \\
\text { (Freeman e Soete, } \\
\text { 1997) }\end{array}$ & $\begin{array}{l}\text { Resultados do } \\
\text { Estudo para Brasil }\end{array}$ \\
\hline Fab. de Produtos Químicos & Intensivo em produção & Ofensiva/defensiva & Dependente \\
\hline Fab. Máq. Ap. e Mat. Elétricos & Intensivo em produção & Ofensiva/Defeniva & Dependente \\
\hline Fab. Máq. e Equipamentos & Fornecedor especializado & Ofensiva/Defeniva & Dependente \\
\hline Fab. Veículos e Autopeças & Intensivo em produção & Ofensiva/Defensiva & Dependente \\
\hline
\end{tabular}

Fonte: Elaboração própria, com base nos resultados da pesquisa

A tabela 4 apresenta os resultados dos indicadores selecionados para o grupo de setores de alta intensidade tecnológica. Nos setores deste grupo, os resultados encontrados para o Brasil revelam que o país possui recursos tecnológicos para inovar em processo e produto nos setores de Fabricação de Produtos Farmacêuticos e Fabricação de Outros Equipamentos de Transporte. No setor de Fabricação de Outros Eequipamentos de Transporte, o Brasil liderou o grupo de países selecionados, tanto no indicador de intensidade em imitação de processo $(1,77 \%)$, quanto no indicador de intensidade em imitação de produto $(3,71)$. Ademais, o país apresentou, também, o melhor desempenho no indicador de intensidade em inovações organizacionais e de marketing $(46,27 \%)$.

No setor de Fabricação de Produtos Farmacêuticos, encontrou-se um padrão similar ao observado no setor de Fabricação de Outros Equipamentos de Transporte. No primeiro caso, o Brasil está entre as economias que possuem desempenho mediano em imitação $(1,21 \%)$ e elevado inovação em processo $(1,92 \%)$ possivelmente refletindo o caráter manufatureiro da indústria nacional, especialmente das subsidiárias de empresas estrangeiras, mas sem estratégias inovativas comparáveis para os produtos. No segundo caso, as relações se invertem no que diz respeito a processo - imitação forte, líder; inovação mediana -, mas ganha relevância a imitação em produto (liderança, muito vinculada às capacitações dos setores de aeronaves, equipamentos ferroviários e veículos militares). Em suma, enquanto o setor Farmacêutico se apresenta com estratégia ativa em processos, Fabricação de Outros Equipamentos de Transporte concentra-se na estratégia de imitação de processos e de produtos. 
Tabela 4 - Indicadores de intensidade em imitação e inovação por setores de alta intensidade tecnológica - Brasil e país com melhor desempenho por indicador

\begin{tabular}{|c|c|c|c|c|c|c|c|c|c|c|}
\hline & \multicolumn{4}{|c|}{ Processo } & \multicolumn{4}{|c|}{ Produto } & \multirow{2}{*}{\multicolumn{2}{|c|}{$\begin{array}{c}\text { Inovações } \\
\text { Organizacionais e } \\
\text { de Marketing }\end{array}$}} \\
\hline & \multicolumn{2}{|c|}{ Imitação } & \multicolumn{2}{|c|}{ Inovação } & \multicolumn{2}{|c|}{ Imitação } & \multicolumn{2}{|c|}{ Inovação } & & \\
\hline \multicolumn{11}{|c|}{ Fabricação de Produtos Farmacêuticos } \\
\hline Brasil & & 1,21 & & 1,92 & & 1,42 & & 2,24 & & 24,41 \\
\hline Líder & Sérvia & 2,26 & Brasil & 1,92 & Sérvia & 3,76 & Alemanha & 10,00 & Macedônia & 50,00 \\
\hline Class $(\%)$ & MB & 53,5 & A & 100,0 & B & 37,8 & B & 22,4 & MB & 48,8 \\
\hline \multicolumn{11}{|c|}{ Fabricação de Equipamentos de Informática, Eletrôncios e Óticos } \\
\hline Brasil & & 0,21 & & 0,48 & & 0,55 & & 1,23 & & 21,58 \\
\hline Líder & Noruega & 0,85 & Noruega & 3,95 & Alemanha & 1,75 & Áustria & 10,76 & Áustria & 50,92 \\
\hline Class (\%) & B & 24,7 & B & 12,2 & B & 31,4 & B & 11,4 & B & 42,4 \\
\hline \multicolumn{11}{|c|}{ Fabricação de Outros Equipamentos de Transportes } \\
\hline Brasil & & 1,77 & & 0,75 & & 3,71 & & 1,57 & & 46,27 \\
\hline Líder & Brasil & 1,77 & Áustria & 1,40 & Brasil & 3,71 & Áustria & 5,88 & Brasil & 46,27 \\
\hline Class (\%) & A & 100,0 & $\mathrm{MB}$ & 53,6 & A & 100,0 & B & 26,7 & A & 100,0 \\
\hline
\end{tabular}

Fonte: Elaboração própria a partir de CIS (2016) e PINTEC (2014)

Obs. Class (Classificação): Médio baixo (MB); Médio Alto (MA); Alto (A); Baixo (B)

O setor de Fabricação de Equipamentos de Informática, Eletrônicos e Ópticos do país apresenta baixo desempenho em todos os indicadores analisados, o que permite classificar a estratégia inovativa deste setor como Dependente, Em função da forte presença de empresas multinacionais estrangeiras neste setor, o baixo desempenho inovativo e imitativo desta atividade no Brasil parece relegar ao país - pelo menos no futuro próximo - o papel de um simples fornecedor do mercado consumidor local.

Em relação aos padrões setoriais de inovação, todos os setores do grupo de alta tecnologia são baseados em ciência (Quadro 4). A apropriabilidade dos benefícios econômicos do progresso técnico provém de patentes, segredos e capacidades específicas às empresas, as quais desenvolvem elevada capacidade para introduzir inovações de processo e produto. Tais características tornam as estratégias ofensivas e defensivas predominantes nestes setores nos países avançados e as estratégias imitativas e, em menor medida, as defensivas prevalecentes nos países bem sucedidos no catching up tecnológico.

\begin{tabular}{|c|c|c|c|}
\hline Alta Tecnologia & $\begin{array}{l}\text { Padrões setoriais de } \\
\text { Inovação } \\
\text { (Pavitt, 1984) }\end{array}$ & $\begin{array}{c}\text { Estratégias de } \\
\text { Inovação } \\
\text { (Freeman e Soete, } \\
\text { 1997) } \\
\end{array}$ & $\begin{array}{l}\text { Resultados do } \\
\text { Estudo para Brasil }\end{array}$ \\
\hline Fab. Produtos Farmacêuticos & Baseados em ciência & Ofensiva/defensiva & Defensiva (processo) \\
\hline Fab. Eq. Informática, Eletr. Óticos & Baseados em ciência & Ofensiva/Defeniva & Dependente \\
\hline Fab. Outros Eq. Transportes & Baseados em ciência & Ofensiva/Defensiva & Defensiva \\
\hline
\end{tabular}

Fonte: Elaboração própria, com base nos resultados da pesquisa.

A análise dos resultados dos indicadores para a indústria brasileira de alta tecnologia permite classificar suas estratégias inovativas como basicamente defensivas, exceto no caso da indústria de equipamentos de informática. A opção pela estratégia defensiva deve-se, nestes casos, ao fato de que, embora o Brasil apresente capacidade para introduzir inovações de processo, o desempenho do indicador de intensidade em inovação de produto é baixo. Segundo Freeman e Soete (1997), nos setores baseados em ciência, a escolha pela estratégia ofensiva/defensiva é fundamentada no desenvolvimento de capacitações para introduzir inovações tanto de processo, com foco nos ganhos de eficiência produtiva, quanto de produto, 
com foco na qualidade buscando a conquista de novos mercados. No caso brasileiro, os setores de Fabricação de Produtos Farmacêuticos e o de Fabricação de Outros Equipamentos de Transporte adotam estratégia defensiva, amparada em inovações de processo (o primeiro) para obter de ganhos de eficiência produtiva e forte imitação em processo e em produto (o segundo). O elevado desempenho da indústria de Fabricação de Outros Equipamentos de Transporte em imitação de produto, embora não permita classificar sua estratégia inovativa como ofensiva, parece indicar que as empresas deste setor podem vir a inovar em produto no futuro.

\section{Observações finais}

Sobre as características básicas das estratégias, parece ser possível destacar as avaliações quanto ao presente complexo e ao futuro incerto - as expectativas e, também, as previsões a ele associadas. Ou seja, as estratégias dizem respeito aos procedimentos a serem adotados - com vistas a atingir os objetivos/metas fundamentais das empresas/organizações -, em condições em que o conhecimento pleno dos eventos futuros é desconhecido e que, portanto, o comportamento dos demais agentes relevantes não podem ser antecipado com certeza ou mesmo com base em uma distribuição de probabilidades equivalente. Isto é, as estratégias são características das condições nãoergódicas (Tidd et al., 2005; Shackle, 1972; Hicks, 1980; Davidson, 2011). Estas circunstâncias são, igualmente, aplicáveis às estratégias inovadoras - especialmente quando estas últimas envolvem, também, a dimensão tecnológica -, uma vez que as incertezas de mercado se somam, ainda, as incertezas relacionadas à técnica.

$\mathrm{Na}$ perspectiva aqui esboçada, estratégias resultam da tomada de decisão adaptativa e sequencial, com eventuais ajustes retroativos, a partir dos feedbacks de desempenho. Esse conceito ganha amplitude com a adição das estratégias inovativas da tipologia de Freeman e Soete (1977). Nesse contexto, este estudo, que procura estabelecer estratégias setoriais (dominantes) a partir da decisão empresarial, pressupõe que elas podem - e frequentemente são - alteradas ao longo do tempo. Em outras palavras, as ações adotadas podem, muito provavelmente, passar por alterações e ajustes.

Adotou-se neste artigo a conjectura metodológica de que as estratégias de inovação podem ser parcial e indiretamente inferidas dos procedimentos observados nos setores industriais, que informam sobre a intensidade em inovação e em imitação - tanto de produto e de processo quanto organizacionais e de marketing. Assim, para tentar estabelecer as estratégias via procedimentos, foram construídos cinco indicadores de inovação e imitação (tabelas 1 a 4), que possibilitaram classificar os 19 setores da indústria brasileira de transformação segundo a taxonomia de trajetórias tecnológicas proposta por Pavitt (1984). Por fim, essas trajetórias tecnológicas foram confrontadas com ao padrão de inovação atribuído a cada indústria a partir da extrapolação da tipologia de inovação desenvolvida por Freeman (Freeman e Soete, 1994) (quadros 1 a 4). Os resultados obtidos demandam, entretanto, alguns comentários importantes que serão feitos no item seguinte.

Em primeiro lugar, os indicadores propostos se mostram, aparentemente, consistentes com a literatura, uma vez que há uma clara tendência de elevação dos seus valores à medida que a intensidade tecnológica setorial aumenta. No entanto, os indicadores apresentam variações dentro e entre as classificações. Esses resultados parecem não conflitar com uma das conjecturas deste estudo, ou seja: recursos e capacidades das firmas podem determinar estratégias inovativas (e tecnológicas) distintas nas indústrias de diferentes países, nem todas elas estritamente compatíveis com as estratégias esperadas para o padrão setorial. Assim, ao revelar "desvios" da estratégia esperada, o estudo parece indicar corretamente casos de fragilidades industriais (estratégias distintas da esperada para a trajetória tecnológica setorial). 
Um segundo comentário diz respeito aos indicadores relativos aos novos métodos de marketing (coluna 5, tabelas 1 a 4). Na quase totalidade dos casos, os indicadores brasileiros se mantiveram entre os mais altos da amostra. Todavia, nos países europeus essas atividades se mostraram elevados apenas nos setores de média alta e alta tecnologia. Assim, e considerando que essas inovações são mais voltadas ao fomento das vendas - e, também, o conjunto de resultados para os outros indicadores -, o Brasil parece estar mais centrado em estratégias de ajustes (reposicionamentos) e esforços de vendas, fato que pode caracterizar um viés para estratégias tecnológicas de baixo perfil com finalidade mercantil imediatistas e pouca ambiciosas. Essa conclusão preliminar é, aparentemente, consistente com os demais resultados,

Em relação ao indicador de intensidade em imitação, os resultados verificados na maioria dos setores investigados não permitem afirmar que o Brasil adote, de maneira ampla, estratégias de intensificação de esforços de imitação (colunas 1 e 3 , tabelas 1 a 4 ) - ao menos metade dos setores apresentam nível baixo (menos de $40 \%$ do índice do país de melhor desempenho) nas atividades de imitação. Situação similar ocorre também com os indicadores de inovação (colunas 2 e 4) - ao menos $60 \%$ dos setores apresentam baixa intensidade nas atividades de inovação. Esses traços dominantes parecem reveladores das estratégias tecnológicas incipientes e da fragilidade competitiva de maior parte da indústria nacional. Os setores de média alta tecnologia, grupo chave para muitos países desenvolvidos, configuram um caso marcante de estratégia tecnológica (e competitiva) brasileira, uma vez que praticamente inexistem atividades inovativas (todos os 4 setores praticam índices baixos) e imitativas ( $7 \mathrm{em} 8$ casos) comparáveis. Em suma, não parecem existir ações claras que possibilitem à maior parte dos setores nacionais alcançar os países que lideram a introdução de inovações de processo e produto.

Algumas exceções merecem comentários. A categoria de baixa tecnologia apresenta casos distintos do padrão nacional dominante. O setor de Papel e Celulose - intensivo em produção e com pouca diferenciação de produtos e onde a indústria nacional melhor se posiciona - detém o melhor desempenho comparativo em inovação em processo e, por atender o padrão de inovação, foi classificado como estratégia ofensiva. A mesma estratégia também foi atribuída ao setor de Fabricação de Bebidas, por apresentar padrão similar em inovação em processo, e, principalmente, por ser inovador em produto. Ressalta-se que as duas indústrias demandam recursos disponíveis no país - terra para reflorestamento, no primeiro caso, água e proximidade ao mercado consumidor, no segundo - e são caracterizadas por forte presença de empresas estrangeiras que usufruem das "vantagens locais". Esses foram os dois únicos casos caracterizados como implementadores de estratégias ofensivas.

Nos demais setores dessa classificação, assim como nos agrupamentos de média baixa e média alta tecnologias, as indústrias foram tipificadas com estratégias aquém do dos padrões setoriais esperados de inovação: respectivamente, com estratégias imitativas, dependentes ou tradicionais, todas traduzindo níveis de atividade inovativas e imitativas inferiores aos casos de referência.

Os indicadores brasileiros de alta tecnologia revelam uma situação, aparentemente, paradoxal. Apesar da debilidade tecnológica das demais indústrias - em particular dos setores de média alta tecnologia -, as atividades inovativas do grupo de alta tecnologia são, relativamente, densas. A insuficiência nas capacitações tecnológicas dos demais setores, parece não prejudicar muito as atividades inovativas no grupo de alta tecnologia. O Brasil é tão peculiar que desenvolver atividades de alta tecnologia parece prescindir, em certa medida, de conhecimentos equivalentes em setores de níveis inferiores de intensidade tecnológica. Esta aparente inconsistência se explica, ao menos parcialmente, pelas características dos setores e das atividades envolvidas.

O setor farmacêutico se revela forte em imitação de processo e fraco em inovação e imitação de produtos, caracterizando, assim, uma 'estratégia ofensiva em processo'. De fato, a forte presença de multinacionais no país - acompanhada de política de transferência de tecnologias das matrizes - associada ao posicionamento das empresas brasileiras no segmento de genéricos, acarreta uma estratégia 'manca' que prioriza a manufatura. Em síntese, não tipifica propriamente uma estratégia ofensiva (ou mesmo defensiva), que envolvem capacidades de inovações tanto de produto quanto de processo, como é predominante nos setores baseados em 
ciência.

A Fabricação de Outros Equipamentos de Transporte adota estratégia que se assemelha à anterior, mas que é claramente focada em imitação de processo e de produto, complementada por atividades (em grau médio-baixo) intensivas em inovação de processo. Nesses termos, em razão da ênfase nas atividades imitativas, este grupo parece adotar uma estratégia basicamente defensiva. Neste último, há alguns setores com empresas nacionais que desenvolveram competências especificas: aeronaves (especialmente), veículos militares e equipamentos ferroviários.

Por fim, o caso lamentável da Fabricação de Equipamentos de Informática, Eletrônicos e Ópticos que apresenta baixo desempenho em todos os indicadores analisados. A sua característica de indústria "maquiladora" - montagem de componentes importados, em grande medida, por filiais de empresas estrangeiras - parece explicar o baixo desempenho inovativo e imitativo dessas firmas no Brasil. Assim, o papel reativo, ou seja, atividades inovativas realizadas apenas se pressionadas pelas matrizes ou pelos contratantes, caracteriza uma estratégia assemelhada à dependente. Cabe lembrar que este setor é fornecedor das "tecnologias básicas" daquilo que está sendo denominado de indústria 4.0.

Se, como se pressupõe neste estudo, as estratégias tecnológicas - que são as bases principais dos procedimentos inovativos - são essenciais para a competitividade e estabelecem, em grande medida, as perspectivas para a indústria de um país, então as fragilidades brasileiras ficam evidenciadas nos resultados aqui apresentados. Em momentos como o atual, de profundas mudanças tecnológicas e institucionais, as estratégias praticadas pela indústria de transformação brasileira têm se mostrado, na ampla maioria dos casos, defasadas e inadequadas e, por isso, demandam ação enérgicas e urgentes das instituições públicas e privadas e das próprias empresas.

\section{Technological Strategies in the Manufacturing Industry in Brazil: a study based on innovative activities}

Abstract: The purpose of this article is to identify the technological strategies adopted in the Brazilian manufacturing industry. Technological strategies were analyzed from the construction of innovation and imitation product and process indicators - in addition to an additional indicator for organizational and marketing innovations. The indicators were applied to 19 sectors of the Brazilian manufacturing industry (PINTEC, 2014) and to the counterparts of a set of selected European countries (CIS, 2016). For the purposes of analysis, the industrial sectors were grouped according to the criterion of technological intensity proposed by the OECD and the results compared with the sectoral innovation standards. The conclusions pointed out that the predominant strategies in the Brazilian industry are passive, to the detriment of active ones.

Keywords: Strategies; Innovation strategies; Innovative activities; Manufacturing industry.

\section{Referências Bibliográficas}

ANCONA, C. Tática/estratégia. In: ROMANO, R. (Dir.) Estado-Guerra. Enciclopédia Einaudi, Vol. 14. Lisboa: Imprensa Nacional, 1989.

ANSOFF, H. I. Corporate strategy: an analytic approach to business policy for grow and expansion. New York: McGraw-Hill, 1965.

ARTHUR, B. W. On Learning and adaptation in the economy. SFI Working Paper: 92-07-038, 1992. 
CAMPOS, B; RUIZ, A. U. Padrões Setoriais de Inovação na Indústria Brasileira. Revista Brasileira de Inovação, v. 8. n. 1, p. 167-210, 2009.

CASTELLACCI, F. Technological Paradigms, Regimes and Trajectories: Manufacturing and Service Industries in a new Taxonomy of Sectoral Patterns of Innovation. Research Policy, $v$. 37, p. 978-994, 2008.

CHANDLER, A. D. Jr. Strategy and structure: chapters in the history of the American industrial enterprise. Cambridge: MIT Press, 1991.

CYERT, R. M.; MARCH, J. G. A behavioral theory of the firm. Englewood Cliffs: Prentice-Hall, 1992.

DAVIDSON, P. John Maynard Keynes. São Paulo: Actual, 2011.

DOSI, G. Sources, Procedures and Microeconomics Effects of Innovation. Journal of Economic Literature, v. 26, n.3, p. 1120-1171, 1988.

DOSI, G.; PAVITT, K.; SOETE, L. The economics of technological change and international trade. Hertfordshire: Harvester Wheatsheaf, 1990.

DOSI, G.; EGIDI, M. Substantive and procedural uncertainty: an exploration of economic behaviours in changing environments. Journal of Evolutionary Economics, v. 1, n. 2, p. 145$168,1991$.

FISHBURN, P. C. Utility Theory and Decision Theory. In: EATWEELL, J. et al. The new Palgrave dictionary of economics. London: Macmillan, 1987.

FOSS, N. J. e STIEGLITZ, N. Modern resource-based theory(ies). In: DIETRRICH, M. e KRAFFT, J. Handbook on the economics and theory of the firm. Cheltenham: E. E, 2012.

FREEMAN, C. e SOETE, L. The economics of industrial innovation. Cambridge: MIT Press, 1997.

GEORGESCU-ROEGEN, N. The entropy law and the economic process. Cambridge: HUP, 1971.

HICKS, J. Causality in economics. Oxford: Basil Blackwell, 1980.

IBGE. Pesquisa de Inovação PINTEc - 2011: instruções para o preenchimento do questionário. Nota Técnica. IBGE: Rio de Janeiro, 2012.

LANGLOIS, R. N. Strategy as economics versus economics as strategy. Managerial and Decision Economics, Vol. 24, ps. 283-290, 2003.

LINDBLOM, C. E. The policy-making process. Englewood Cliffs: Prentice-Hal, 1980

LOASBY, B. J. Capabilities and strategy: problems and prospects. Industrial and Corporated Change, Vol. 19, № 4, pp. 1301-1316, 2010.

LAWSON, T. Economic and reality. London: Routledge, 1997.

MARSILLI, O. The Anatomy and Evolution of Industries. Northampton: E.E, 2001.

MARSHALL, A. Principles of economics. (versão digitalizada) London: Macmillan and Co. 8th ed., 1920.

MCFADDEN, D. Rationality for economists? Santa Fe Institute, Working Paper n. 98-09-086, 1998.

MINTZBERG, $\mathrm{H}$. et al. The strategy process: concepts, contexts, cases. Englewood Cliffs: Prentice-Hall, 2006.

MINTZBERG, $\mathrm{H}$. et al. Strategy safary: a guided tour through the wilds of strategic management. New York: Free Press, 1998.

MORRONI, M. Knowledge, scale and transactions in the theory of the firm. Cambridge: CUP, 2006.

NELSON, R. R. The Sources of economic growth. Cambridge: HUP, 1996. 
NELSON, R. R.; WINTER, S. G. An evolutionary theory of economic change. Cambridge: HUP, 1982.

OECD. Oslo Manual. Paris: OECD, 2005.

PAVITT, K. Sectoral patterns of technical change: towards a taxonomy and a theory, Research Policy, v.13, p.343-373, 1984.

PAVITT, K. What we know about the strategic management of technology. California Management Review, v. 32, n. 2, p. 17-26, 1990.

PAVITT, K.; STEINMUELLER, W. E. Technology in corporate strategy: change, continuity and the information revolution. In: PETTIGREW, A. et al. Handbook of strategy management. London: Sage Publications, 2002.

PORTER, M. Competitive strategy: techniques for analyzing industries and firms. New York: Free Press, 1980.

ROSENBERG, N. On technological expectations. In: ROSENBERG, N. Inside the black box: technology and economics. Cambridge: CUP, 1982.

RUMELT, R. P. et al. Strategic management and economics. In: Strategic Management Journal, v. 12, p. 5-29, 1991.

SCHUMPETER, J. A. History of Economic analysis. Nova York: OUP, 1994.

SCHUMPETER, J. A. Capitalism, socialism \& democracy. London: Routledge, 2003.

SCHUMPETER, J. A. Business cycles: a theoretical, historical, and statistical analysis of the capitalist process, v. 1 e 2. Mansfield: Martino Publishing, 2005.

SEN, A. K. Rational Behaviour. In: EATWEELL, J. et al. The new Palgrave dictionary of economics. London: Macmillan, 1987.

SHACKLE, G. L. S. Epistemics and economics: a critique of economic doctrines. Cambridge: CUP, 1992.

SIMON, H. A. Strategy and organization evolution. Strategic Management Journal, v.14, p. 131-142, 1993.

SIMON, H. A. Decision Making and problem solving. Report of the research briefing. NAS, 1986.

SIMON, H. A. Rational Decision Making in Business Organizations. The American Economic Review, v. 69, n. 4, p. 493-513, 1979.

SIMON, H. A. Reason in human affairs. Stanford: SUP, 1983.

TEECE, D. et al. Dynamic capabilities and Strategic Management. Strategic management Journal, v. 18, n. 7, p. 509-533, 1997.

TEECE, D. Explicating dynamic capabilities: the nature and microfoundations of (sustainable) Enterprise performance. Strategic management Journal, v. 28, p. 1319-50, 2007.

TIDD, J. et al. Managing innovation: integrating technological, market and organizational change. Hoboken: John Wiley \& Sons, 2005.

TVERSKY, A. e KAHNEMAN, D. Judgment under uncertainty: heuristics and biases. Science, v. 185,4157 , p. 1124-31, 1974.

VERCELLI, A. Methodological foundations of macroeconomics: Keynes \& Lucas. Cambridge: CUP, 1991.

WHITTINGTON, R. What is strategy and does it matter? Hampshire: Cengage Learning, 2001. 